\title{
Using innovations to understand tourist mobility in national parks
}

Assoc.Prof. Anne Hardy, Private Bag 22, College of Arts, law and Education, University of Tasmania, Hobart, Tasmania, Australia 7001. Email: Anne.Hardy@utas.edu.au. Phone: +61 3 62267687.

Dr Jagannath Aryal, Private Bag 87, Geography and Spatial Sciences, University of Tasmania. Email: Jagannath.Aryal@utas.edu.au.

Associate Professor Anne Hardy is the Director of the Tourism Research and Education Network (TRENd) at the University of Tasmania. She is currently undertaking research in three areas: the neo-tribal behaviour of tourists; sustainable tourism; and tracking tourists' movement using integrated GPS tracking and survey technology. Dr Hardy is the lead investigator on the Tourism Tracer project (www.tourismtracer.com) that has received international acclaim and won numerous awards; it is the first research project to track tourists across an entire destination for the duration of their stay. Dr Hardy's research has been published widely in academic journals, books and via a variety of media channels. Dr Hardy's approach to research seeks to extend knowledge in a two way direction between the tourism industry and academia.

Dr Jagannath Aryal is a Senior Lecturer in Spatial Sciences at the University of Tasmania. His current research focus is on application of spatial and temporal analysis in understanding various processes within data analytics environment. The application areas are tourist behaviour, and information extraction in hierarchy from Earth observation images with an emphasis on environmental management. Dr Aryal's research has been published widely in high impact spatial sciences and highly technical IEEE academic journals. Dr Aryal is the investigator on the Tourism Tracer project overseeing the spatial and temporal aspects. Dr Aryal's research contributes towards advancing knowledge in Geographic Information (GI) Science and Earth Observation data modelling. 


\begin{abstract}
Technological advances have had profound impacts upon tourists' mobility. However, until recently, there has been a gap between technological advances and their integration into tourism research methods. This paper addresses this gap by presenting a research method that utilised an application (app) equipped with a synthesised demographic survey and Global Navigation Satellite System (GNSS) technology. This enabled automated tracking of tourists' behaviour for their entire stay within the island state of Tasmania, Australia. This paper focuses on tourists' movement within the wellknown Freycinet National Park. The highly detailed granular data was assessed in three phases, revealing segments of tourists more likely to use the walking tracks, those more and less likely to visit during peak crowding times and finally, the development of an automated spatio-temporal dependence model via a machine-based learning environment, designed to operate in real time. The paper details the implications that innovative methodologies such as this may offer natural resource managers and tourism authorities, particularly in terms of locating, assessing and ultimately alleviating crowding and overtourism.
\end{abstract}

Keywords: visitor mobility, GNSS technology, national parks, tourist movement, visitor tracking, crowding

\title{
Introduction
}

Currently, the issue of tourist mobility and particularly that which is perceived to create crowding and overtourism is taking centre stage in media outlets across the world. Stories of crowding on Mount Everest, and overtourism in Venice and Barcelona have dominated tourism related media in 2019. A strong desire to mitigate these impacts appears to be taking momentum. Yet, while, the nature of travel has changed dramatically due to the ubiquitous use of smart phones, both in our daily lives and while travelling (Wang et al. 2012, 2014) and while this profound change has been reported as impactingd tourists' planning, decision- 
making and behaviour (Gretzel et al. 2015; Wang and Fesenmaier 2013), innovations in tourismresearch methods have not capitalised on smart phone use, in order to assess and ultimately alleviate the impacts of tourist mobility. This gap is gradually being addressed; recent research has considered the potential (Wang et al. 2013; Heerschap et al. 2014; Lenormand, et al. 2014; Barbosa et al. 2018; Lenormand and Ramasco 2016) and pitfalls of the use of Big Data that may be generated from smart phone usage (Buhalis and Amaranggnana 2014) when tracking the mobility of travellers. However what still remains is the ability to 'fine-tune' this data to granular levels, so that the mobility of different segments of tourists may be explored with optimal granularity of data and with minimal time delays between the collections and analysis of data. In the context of national parks, insights from new technology are paramount for natural resource managers, as they offer the potential to undertake evidenced-based decision making that can ultimately avoid crowding.

Within tourism and recreation research, tourists' mobility within national parks has been explored via Global Navigation Satellite System (GNSS) technology (see Hallo et al 2012; Beeco and Hallo, 2014). This has resulted in an understanding of tourist flow through parks, but so far, the vast majority of these studies have been conducted via manual integration of surveys with GNSS technology, which often require tourists to undertake two tasks: complete a survey and carry a device (e.g. Sugimoto et. al 2019). Consequently, there is a long delay between data collation and data analysis and visualisation. This research tackles this dearth, as it involved the design and use of a research application (hereafter referred to as 'app') that included integrated social survey questionnaire and GNSS technology. The app tracked the movements of over 450 tourists through the island state of Tasmania, Australia, for their entire stay, with their consent. It was then visualised in close to real time, as soon as tourists left the island (see www.tourismtracer.com). More importantly, 
this research resulted in the development of an automated, machine-based learning model that was capable of assessing tourists' mobility in real time.

The focus of this research is on Freycinet National Park, the most highly visited protected area on the island, located on the east coast of the state. At the time of the data collection, the national park was under significant pressure, receiving 300,000 visitors each year, with the majority arriving in summer. The infrastructure within the park was suffering; the major car park, which serves as the hiking hub for tourists, was overcrowded and managers sought solutions to this issue. Added to this, there was uncertainty as to how different cohorts of tourists were using the tracks within the park. These dilemmas provided the impetus for this research. The outcome of this research is a significant methodological contribution in the form of an app, plus a machine-based learning model that when used together, can automatically collate and analyse data in close to real time. Moreover, we highlight how novel digital research methodologies may be used to progress the study of sustainable tourism through a detailed understanding of tourists' mobility.

\section{Methodological approaches to exploring mobility}

Within the broader sustainable tourism literature, efforts to understand the mobility of visitors is gaining momentum. It has been argued that the tradition approaches of assessing sustainable tourism from local and environmental issues is too limited and overlooks the issues of tourist mobility, which has been largely been treated as an entirely different research theme (Høyer 2000). Placing tourism mobility at the heart of tourism research has been posited as a means to ensure that the totality of tourism impacts in both time and space may be examined (Hall 2005). It has been argued that three streams of sustainable tourism mobility research existed (Verbeek and Mommaas 2008). One was concerned with the technological issues of tourism mobility, resulting in a large body of work that assesses the 
sustainability- or otherwise- of differing mobility options (Høyer 2000; Böhler et al 2006: Peeters et al 2004; Gossling et al. 2005 . Boon et al. (2007 and Peeters et al. (2007), w). The second stream focusses on the attitudes and behaviours of tourists to sustainable mobility (Becken (2004 Friedl et al., 2005), Bohler “ et al., 2006; Gotz “ et al., 2003; Schubert, 2004 Friedl et al. (2005)). A third body of work in mobility assesses the characteristics that explain or predict travel mode and the factors that influence changes in travel mode (Guiver et al. (2007; Anable, 2005; Dickinson \& Dickinson, 2006; Robbins \& Dickinson, 2007; Steg \& Vlek, 1996). The focus of this research is on this third domain and the methods that facilitate research in this space.

Prior to this research a number of different methods have been used to undertake research in this mode

The most traditional method for understanding the mobility of visitors has been via direct observation. This method involves a researcher physically following, observing and recording the movement of visitors. It offers the added benefit of being able to record and collate insights into decision-making and group dynamics (McKercher and Lau 2009). However, this method has been critiqued as being potentially invasive, ethically questionable if consent is not gained (Valance 1995; Thimm and Seepold 2016), time consuming, expensive and consequently resource-intensive (McKercher and Lau 2009; Edwards et al. 2010). These restrictions may be overcome via an alternative non-technological approach, whereby tourists self-record their mobility via trip diaries or maps (e.g. McKercher and Lau 2009; Thornton, Williams and Shaw 1997; Janelle and Goodchild 1988). The technique requires participants to record their route and stops, plus activities, via a daily travel diary or on a map within a survey. As well as being unobtrusive, this technique can elicit fine-grained insights into tourists' movement (Lew and McKercher 2006; Shoval et al. 2011; Connell and Page, 2008). Following tourists' recording of their movements, these data can be stored, 
cleaned and visualised using Geographical Information System (GIS) software. During the spatial analysis process GIS software can be used to explore trends in behaviour and differences between and within tourist segments. This method was used by Shoval, Isaacson, Chhetri (2014). However, the accuracy of the data collected by this method largely depends on tourists' recall and commitment to the research program (Thimm and Seepold 2016; Shoval and Isaacson 2006; Modsching et al. 2008; Beeco, Huang et al. 2012).

In the past 60 years, since the launch of Global Positioning Satellites (GPS) by the United States Department of Defence in 1973, its development and application in multidisciplinary areas has been expanded. GNSS trackers were initially designed as hand held devices that participants would be required to carry. Researchers have used these to track tourists in Virginia (Beeco et al 2013), understand different types of recreational use of protected areas in South Carolina (Hallo et al 2012; Beeco and Hallo, 2014), track tourists' movement in Melbourne and Sydney (Edwards and Griffin, 2013), Hong Kong (Shoval et a; 2011), assess cross country ski racers' locations in Victoria, Australia (O’Connor, Zerger and Itami 2005) and to track cruise ship passengers' movement when onshore in Palermo (De Cantis et al 2016). However, what has been noted is that GNSS has rarely been used to do more than visually depict movement and that a dearth in research exists that assesses mobility patterns and, significantly, the factors that are associated with differences in movement (Beeco and Hall, 2014). One reason for this gap is that the labour and precision required to synchronise GNSS tracking data manually with survey data means that the methods are labour-intensive and consequently expensive to conduct with a high precision.

To overcome this, tracking via mobile phone data has recently been explored to understand mobility. While several options exist including tracking via unique identifiers (Shoval and Isaccson 2010) or when phones pass by WiFi or Bluetooth receivers (Versichele et al 2014), these techniques are limited in the ability to decipher tourists' behaviour and 
socio-demographic characteristics. More recently, GNSS technology embedded within applications has been developed. This method offers an alternative that has the potential to elicit far more accurate data on the mobility of tourists (Wang, Park and Fesenmaier 2012; 2014; Dickinson et al 2013; Hardy et al 2017). Indeed, it has been suggested that this method has the potential to revolutionise tourist tracking research by lowering the cost of data collection, increasing accuracy of participants' location and mobility data and minimising the inconvenience to study participants (Yun and Park 2015). Further, when automated, GNSS embedded technology can be visualised via data dashboards in real time. Its ability to track continuously sets it apart from Internet Protocol addresses (IP addresses), which are numerical identifiers attached to mobile phones that provide course location data or data sourced via transceivers, particularly when combined with surveys, as it can produce highly detailed data on differences in tourists' movement patterns according to their psychographic characteristics (Hardy et al 2017; Dickinson et al 2013; Asakura and Iryo 2007; O’Connor, Zerger and Itami 2005). However, while apps equipped with tracking capabilities are a natural fit for tracking studies (Hardy et al 2017), they require consumers to consent to sharing information on their movement (Dou, Eklund and Gretzel 2016). For many businesses, consent is sought via user agreements that offer services in return (Hardy et al 2017; Dou, Eklund and Gretzel 2016). Not surprisingly, the use of app-based tracking for research purposes is ethically problematic as it requires informed consent and in some cases, consumers are not even aware of their potential privacy losses (Anuar and Gretzel 2011; Versichele et al. 2014). The 2018 Cambridge Analytica scandal was a pivotal moment in highlighting this issue, when Facebook users' data was used illegally by Cambridge Analytica to influence election results in several countries (Hardy et al, 2019). There are also concerns that informed consent of tracking may result in participants changing their behaviour (Winters et al. 2008) and its expense is described as a significant limitation 
(Shoval et al. 2014). Attempts to recruit tourists via research apps has been mixed: a 2007 research project in Lake Constance, Germany, failed, largely due to participants' unwillingness to participate (Thimm and Seepold, 2016). Yet, in Korea, a research app successfully tracked festival goers for 5 days (Yun and Park, 2015). It appears that the success of this method largely depends on participants' willingness to be tracked, along with the equipment and incentives used by researchers to encourage participants to share their movement data.

In summary, while a plethora of options existed to undertake tracking via new technology, at the time of project design, there was no ideal method to explore tourist mobility in an outdoor context such as a national park. The challenge for the research team was to design an innovative solution that would determine with great precision, how national park infrastructure was used, when it was used and who used it, in order to assist park managers while at the same time ensuring that tourists would engage with it. Given the limitations of existing technology, it became apparent that an innovative methodological solution was required.

\section{Case study srea: Freycinet National Park}

Freycinet National Park is situated on the east coast of the island state of Tasmania, located to the south east of the mainland of Australia. The area that now comprises the national park was first protected in 1906 as a game preserve. In 1916, Freycinet Peninsula and Schouten Island were declared a Scenic Reserve, making Freycinet National Park one of the oldest national parks in Tasmania. Since then, additions to the park have been made, including the Friendly Beaches and the Wye River region to the north. Freycinet National Park now comprises a total area of approximately 16,803 hectares. The national park is renowned for its pink coloured granite mountains, white sand covered beaches and azure coloured water and 
receives much media attention. The park is experiencing rapid growth in visitation, from 146,000 in 1998 to 310,000 in 2017-2018 (Tasmania Parks and Wildlife Service, 2018). Of

particular concern is the infrastructure in the park; each year it has been anecdotally reported that the majority of visitors to the park make the one and a half hour return walk to the Wineglass Bay Lookout resulting in the tracks, toilets and car parks becoming overcrowded. These concerns were exacerbated by a lack of knowledge into how frequently the tracks within the park were being used and by whom and whether it would be possible to alter visitor behaviour through the use of this knowledge. The impetus for this research came out of these concerns.

\section{Methods}

The data for this study was sourced from a larger project that tracked the movements of free independent holiday tourists in the state of Tasmania, Australia, during 2016. Given the limitations of the methods assessed above, a new technique for collecting tracking data was devised. A bespoke smartphone app with GNSS was created which contained an exit and entry survey and tracking capabilities. The entry survey sought information on the visitors' demographic profile, intended length of stay, primary trip purpose and travel party composition. The exit survey assessed their expenditure and social media usage. The tracking capabilities within the app were designed to collect data on their location every ten seconds, without draining the study phones' battery. This frequency of data collection was similar to previous research that demonstrated that 15 second tracking intervals were suitable for assessments of visitors' movement within protected areas as they are able to capture changes in behaviour, while not producing an overly burdensome amount of data (Beeco and Hallo 2014). The app was loaded onto a Samsung Galaxy S3 smartphone (hereafter referred to as the 'study phone'), as well as three gigabytes of data, that acted as an incentive for 
participants to take part. The study phone could be tethered via the hotspot function to participants' individual phones so that they could use the data via their own device. Participants were recruited at the three major entry ports on the island; Hobart, Launceston and Devonport. They were asked to keep the study phone turned on at all times, for the duration of their travels. This methodological approach and the decision behind the choice of technology, including its constraints and limitations, have been discussed in detail in Hardy et al (2017). The design of its close-to-real-time visualisation via the www.tourismtracer.com dashboard is also discussed in Hardy et al (2019). In total 472 tourists who were in the state for between four and 14 days participated in the study. Tourist were recruited between February and May — the peak tourist season in Tasmania. The end result was the largest GNSS data set of its type in tourism research, both temporally and spatially.

The original point location data collected in the first stage of the University of Tasmania's Tourist Tracking Project was recorded at a frequency of one location every 10 seconds. Synchronisation of temporal frequency of collected data with different social questions was achieved using temporal aggregation of 10 seconds data. It was determined that fine temporal grain was is not necessarily optimal in answering various social science questions, therefore analysis was undertaken using a cleaned and aggregated version of this data with a collection frequency of one location every one minute. Algorithms were developed in R statistical computing language environment after cleaning and aggregating the data.

The focus of this research was the Freycinet National Park and specifically the walking tracks that led from the major tourist node, the Wingless Bay Car Park. Of the 472 participants of the study, 219 visited the national park. 157 participants used the Wineglass Bay Car Park and of those, 91 walked up the track to the Wineglass Bay Lookout. Of all the 
visitors, the average amount of points captured in the park was 812 per visitor. In order to assess the use of infrastructure the data analysis focussed on three main issues:

(i) determining the segments of tourists using the network of short walks offered through the Freycinet National Park;

(ii) determining how the car park infrastructure was used; and

(iii) visualising the spatio-temporal dependence of tourist mobility. Ready-to-analyse data were further cleaned and treated for statistical analysis in the R computing environment. Selected dependent and independent variables and their significance were analysed in STATA software environment. Analysis for various segments was undertaken in a GIS environment using ArcGIS software. Following this, the spatio-temporal dependence model was developed by visualising spatial and temporal properties in a machine-based learning environment. These were contextualised within proximity and timegeography theory.

\section{Results}

\section{Profile of participants in Freycinet National Park}

The average age of the Freycinet visitor was similar to tourists who took part in the overall study; the state-wide average from the data set collected via this study was 46 years old whereas the average Freycinet visitor was 44.

In terms of nation of residency, five percent of the visitors were Australian residents, compared to the $63 \%$ of the study as a whole. $6.4 \%$ of the other (ie, non-Australian resident) Freycinet visitors were from mainland China, 7.7\% from Hong Kong and 31\% were from other overseas countries.

In order to explore who used the walks within the Freycinet National Park, variables were created with the following categories: 
$0=$ Did not do any walks

$1=$ Did a walk

A number of independent variables were examined, including: age; length of stay on the Freycinet peninsula; length of stay in Tasmania; location of previous overnight; walks undertaken on the Freycinet peninsula; travelling with children; travelling as a couple; first time or otherwise visiting Tasmania; reason for visiting Tasmania; Tasmania as the only or main destination; gender; place of residence; education and employment status. We used the bivariate analyses — a Chi-square test - to test the relationship between dependent and discrete independent variables. Whereas, we used the t-test to test the relationship between the dependent variables and continuous independent variables.

Of these variables, the following were found to have significance. First, age was a significant variable in that younger visitors to the Freycinet Peninsula were found to be more active than older visitors (Figure 1).

[Figure 1: Percentage of walkers who did or did not do any of the walking tracks, by age - to go here]

Secondly, compared to tourists visiting for other reasons, those who were in Tasmania to see wilderness and wildlife were more likely to take a walk. Place of residence was also found to be significant, with visitors from Australia and Mainland China being less likely to do a walk, while visitors from Hong Kong and other international countries were more likely to do a walk (Figure 2).

[Figure 2: Percentage of visitors who did or did not do any walking tracks, by place of residence - to go here]

\section{Dispersal within the pPark}

Following analysis of who walked, we sought to understand which were the most common 
walking routes: a walk from car park to the Lookout and back (with an option to continue to the Wineglass Bay beach); or secondly, a loop that includes the Lookout plus beach and then continues around to the eastern side of the peninsula (see Figure 3).

[Figure 3: Freycinet National Park walking tracks - to go here]

To measure dispersal, we created variables with the following categories:

$0=$ Participants who only did the Lookout and Wineglass Bay walking tracks; and $1=$ Participants who did the whole loop

Once again the independent variables that were examined included: age; length of stay on the Freycinet peninsula; length of stay in Tasmania; location of previous overnight; walks undertaken on the Freycinet peninsula; travelling with children; travelling as a couple; first time or otherwise visiting Tasmania; reason for visiting Tasmania; Tasmania as the only or main destination; gender; place of residence; education and employment status.

The most defining factor in determining whether walkers did the loop or the Lookout and/or Wineglass Bay walk was the number of hours they spent at the Peninsula. The percentage of walkers doing the loop increased as the number of hours they spent at the Freycinet Peninsula increased (Figure 4).

[Figure 4: Percentage of walkers who did shorter and longer walks, by number of hours at the Peninsula - to go here]

Overnight stays on the Freycinet Peninsula were also found to be significant. Walkers who stayed on the Freycinet Peninsula overnight the night before they walked (such as in the small township of Coles Bay) were more likely to do the loop than those who did not spend the night before their walk on the Peninsula. A further final variable that was found to be 
significant was tourists' stated reason for visiting Tasmania. Those who stated that their primary reason to visit the island state was to see wilderness and wildlife were, compared to tourists visiting for other reasons, more likely to complete the loop.

\section{Use of car park infrastructure}

In order to assist the natural resource managers understand crowding in more detail, our analysis explored three factors relating to uses of the car park:

1. The length of time visitors (or their cars) occupied the car park;

2. The time of day visitors arrived and departed from the car park; and

3. The characteristics of all visitors who used the car park and of those who used the car park in peak times $(11: 00 \mathrm{am}-2: 00 \mathrm{pm})$.

In addition to the above, the analysis also examined other surrounding park use by tourists who used the car park. Specifically, the analysis focused on three aspects:

4. Which walks visitors to the Wineglass Bay Car Park undertook from the car park;

5. Other places these tourists visit in the national park; and

6. Where these visitors stay the nights before, during and after their visit to Freycinet National Park.

From this dataset, all locations reported on the Freycinet Peninsula south of the intersection of Coles Bay Road and Apsley River were extracted. Points were then split into those collected on land (FPLand) and those collected on water (FPWater) using the Local Government Area boundary developed in GIS environment. Using this land-based Freycinet Peninsula dataset (FPLand), car park users were then identified by extracting all points from within an area defined as the car park and surrounds. This dataset contained 157 car park users. An additional dataset containing these car park points and all points on the tracks accessed from the car park (all points on the Mount Amos track and the Wineglass Bay track 
loop) was also created. This dataset contained the same 157 tourist phones. This 'Wineglass Bay car park and track points' data was then used to assess tourist car park use rather than just the 'Wineglass Bay car park data'. Following an initial assessment of the data it was noted that no tourist stayed overnight in the park (i.e. camping). Of the 157 tourists using the car park, five used the car park on two days and one used the car park on three days, and 151 tourists were single day visits. Given the above, use of the car park was assessed on a day use basis meaning the six multi day use tourists were assessed based on 13 individual trips. Thus, the total number of car park usages examined was 164 .

Using the FPLand dataset, all points within the Freycinet National Park were then examined. The walks or park areas identified were split between those that were accessed from the Wineglass Bay Car Park and those that were not. Activities or areas accessed from the car park included the Wineglass Bay Lookout, Wineglass Bay track to beach camp track (excluding the lookout), Mount Amos walk, Wineglass Bay Beach and Fleurieu Point (the loop walk between Hazards Beach and Deep Gap Creek). Walks / Areas are shown in Figure 3. The presence (at any time) of phones that had been in the car park within these areas was added to the table of phone and survey information on car park access times.

Following this, each car park use within the 'Wineglass Bay car park and track points' data, the time of arrival, departure and total length of stay, were extracted. Arrival and departure times were determined by identifying the first and last point in the 'Wineglass Bay car park and track point's dataset. If a phone stopped in the park (i.e. the battery ran flat) then time of departure would be underestimated. However, this was deemed the only suitable way of dealing with the issue of phones stopping prior to returning to the car park. Tourists using the car park between 11:00 am and 2:00 pm were also identified by selecting the subset of tourists who arrived at the car park after 2:00 pm or who left before 11:00 am. Using these times, a new table was created in ArcGIS environment and the distribution of their car par 
usage time was visualised. This dataset was then integrated with demographic and tourist behaviour information collected during the survey for each tourist.

The overnight location of the 157 car park users was then examined for the period they stayed on the Freycinet Peninsula. From the state-wide one minute dataset, the first recorded location on each day for the 157 tourists was extracted. Using the full FP dataset the time of arrival and departure from Freycinet Peninsula was determined. Then the first location on the day of arrival to Freycinet Peninsula and the first location on the day after leaving Freycinet Peninsula were assigned 'before' and 'after' trip status. All nights in between were assigned 'during' trip status. The data quality was checked as a few tourists visited the Freycinet Peninsula on more than one occasion. It should be noted that only trips where the car park was used were included in the assessment.

As outlined above, a total of 157 car park users were identified on a total of 164 car park use days. No tourist in this investigation stayed overnight in camp grounds in the park or left their car at the car park. All occupations of the car park are presented in Figure 6. All times and time periods are presented in 24 hour decimal time.

The average length of time all visitors occupied the car park was 1.89 hours \pm standard deviation of 1.65 hours. Figure 5 shows a histogram of occupation time in the car park for all 164 occupation periods. The distribution is clearly skewed towards many short period visits and a similarly large number of longer (variable length) visits with a peak visit duration of between 1.5 to 2 hours.

[Figure 5: Time spent in car park for all occupation periods - to go here] 
The average arrival time for all visitors was 12.48 (12:29 pm). However, the peak arrival time is closer to 11:00 am as presented in the distribution graph. The average departure time was $14.38(2: 23 \mathrm{pm})$.

Of the 164 use days a total of 109 occupations were between the peak periods of 11:00 am and 2:00 pm (i.e. the tracker arrived at the car park after 11:00 am or left before 2:00 pm). The average length of time these peak time visitors occupied the car park was 2.3 hours \pm standard deviation of 1.72 hours. It became evident that there were fewer short-term visitors (visitors who stayed less than $30 \mathrm{~min}$ ) during this period. The average arrival time for visitors using the car park between 11:00 am and 2:00 pm was 11:38 am. The average departure time for these tourists was 1:56 pm.

The analysis then explored the demographic and other travel behaviour information of the tourists who visited Freycinet Peninsula, the Wineglass Bay Car Park and tourists who used the car park between 11:00 am and 2:00 pm. The demographic variables that were explored included: age; highest level of education and employment status; reason for visit to Tasmania; place of residence; if the tourist had previously visited the state; main form of transport; and travel party size and composition. The analysis revealed that there was a slight tendency for tourists above 60 years of age to use the car park during peak periods and for tourists less than 29 and between 40 and 59 to avoid the car park during those periods. However, these trends were relatively weak. The analysis also revealed that there was a dominance of tourists whose primary motivation was to visit Tasmania to experience wilderness and wildlife, amongst those that visit the Peninsula. Significantly, a proportion of these people appear to avoid the car park during peak periods.

Our analysis revealed a dominance of Australian and Hong Kong residents in the sample of visitors to Freycinet Peninsula. Of the Chinese tourists recorded in the car park, only three out of eleven used the car park during peak hours. Other groups (tourists from 
Australia, Hong Kong and tourists who identified themselves as being from 'other international countries') used the car park facility during peak hours as well as off-peak hours. The car park usage during peak hours was more than half of the total car park usage time.

Our analysis revealed that first-time visitors dominated the sample of tourists who visited the Peninsula, but this was not dominant in car park usage. Similarly, while we found a dominance of car/4WD renters followed by a large group of people with their own cars/4WDs using the car park, there was no clear effect of this factor on car park use during peak periods.

There was also a dominance of working and retired couples with degree or higher degree education levels visiting Freycinet Peninsula. However, again no influence on car park usage times was evident in any of these factors.

Following this, we assessed the period of time that tourists (or their cars) occupied the Wineglass Bay Track Car Park. We assessed all tourists who used the Track Car Park and all tourists who used the car park between 11:00 am and 2:00 pm. An overriding trend was that the average time spent using the car park tended to increase for those who used the car park during peak hours as compared to the complete car park using cohort. Moreover, the time spent in the car park decreased with age, excluding the eldest group (tourists greater than 70 years) where time spent using the car park was the greatest.

[Figure 6: Time using car park by age - to go here]

The analysis also revealed that Chinese tourists spent the shortest time using the car park whereas tourists from other overseas countries who used the car park during peak hours 
spent the longest periods in the car park. Australian and Hong Kong tourists occupied the car park over similar time periods.

Further, smaller groups spent longer using the car park than larger groups. Similarly, less time was spent using the car park by people travelling as a family with children. There appeared to be no clear effect of previous visitation to Tasmania, the form of transport being used, education level or employment status on time spent in the car park.

\section{Overnight locations of visitors using the Wineglass Bay Track Car Park}

The GNSS data allowed the research team to determine the overnight locations (as first location reported on each day) of tourists the morning of their day of arrival at the car park, and on the evening of the day the tourist left the Peninsula (Figure 14). While there was no detectable pattern in, before or after trip overnight locations, it was clear that tourists' overnight location for their nights prior to their time in the car park and after their visits on Freycinet Peninsula, appeared to be as close as possible to the entrance of the national park. These tourists were recorded no further than the towns of Swansea and Bicheno.

[Figure 7: Overnight locations of tourists using the car park before and after visiting the Freycinet Peninsula - to go here]

Significantly, the analysis revealed that there were high concentrations of tourists staying on the East Coast, and in Hobart to the south and Launceston to the north.

Given the limited scope of exploratory and descriptive statistical analysis and the requirement for manual cleaning and analysis to be undertaken, we sought to develop a model to assist in visualising tourists movement through time and space via machine-based learning. This is discussed in the following section. 


\section{Spatio-temporal dependence model of tourist mobility}

Using a machine-based learning environment and the open source Jupyter platform, space and time (i.e. spatio-temporal dependence) were considered using proximity theory and modelled for nearby and distant spatial properties. Temporal dependence was also considered and modelled for closeness, period, and trend properties.

In any mobility setting, the inflow (entry) of a crowd in a region is affected by outflow (exit) of crowd in nearby regions, such as when a tourist leaves one region to go into another region. The flow can also be affected by that of distant region, such as when tourists travel a far distance from their hotel to visit tourist attractions. Similarly, when considering the temporal dependencies, the flow of tourists is affected by their time of arrival. For example, number of tourists' who arrive at 9.00 am affects visitation at subsequent sites at $10.00 \mathrm{am}$. This was modelled as a 'closeness' temporal dependency. The other dependency that was modelled was 'period', such as tourist arrivals at opening / closing hours, can resemble a pattern. The third temporal dependency that was modelled was 'trend'- where the flow follows a certain trend with a change in time, such as changes caused by extended daylight hours during summer time.

Finally, in any region, the inflow and outflow of the tourists at certain time interval are defined by total number of tourists entering and exiting the region. To calculate inflow and outflow, we used an algorithm based upon Relative Complement from Set Theory. Definition - Relative Complement: If A and B are sets, then the relative complement of A in $\mathrm{B}$ is the set of elements in B but not in A. The relative complement of A in B is denoted by B $\backslash$ A.

FORMALLY: $\mathrm{B} \backslash \mathrm{A}=\{\mathrm{X} \in \mathrm{B} \mid \mathrm{X} \notin \mathrm{A}\}$

Inflow/outflow Calculations 
$\mathrm{A}=\mathrm{Num}_{\mathrm{t}-1}=$ Total number of tourists in any region $\mathrm{R}$, at time instance $\mathrm{t}-1$.

$\mathrm{B}=\mathrm{Num}_{\mathrm{t}}=$ Total number of tourists in any region $\mathrm{R}$, at time instance $\mathrm{t}$.

$\mathrm{R}_{\text {Inflow }}=\mathrm{B} \backslash \mathrm{A}=\mathrm{Num}_{\mathrm{t}} \backslash \mathrm{Num}_{\mathrm{t}-1}$

$\mathrm{R}_{\text {Outflow }}=\mathrm{A} \backslash \mathrm{B}=\mathrm{Num}_{\mathrm{t}} \backslash \mathrm{Num}_{\mathrm{t}-1}$

After calculating the inflow/outflow of tourists in any region and at any time instance, we implemented this algorithm into the model for simulation and visualisation.

\section{Interpretation of the machine- based learning model}

A deep learning approach was used to develop the model. Deep learning has been used in for many applications in recent years, including speech recognition, visual object recognition, and semantic segmentation (Garcia-Garcia et al. 2018; LeCun, Bengio, \& Hinton, 2015). In general, two main types of deep learning models are used in spatial-temporal applications: 1) convolutional neural networks (CNNs) in order to capture spatial structures; and 2) recurrent neural networks (RNNs) for learning temporal dependencies. The overall architecture was based on that developed by (Zhang et al. 2018) which is modified for national park setting. The computational steps that were undertaken were as follows: inflow (entry) and outflow (exit) for each region at each time interval was calculated as a 2-channel flow matrix. The 2channel flow matrices of intervals in each time fragment were then fed into the three components separately to model the three temporal properties: closeness, period and trend. Time axis was divided into three components, denoting recent time, near history and distant history. The three components consisted of a convolutional neural network followed by a residual unit sequence to capture the spatial dependency between nearby and distant regions. The outputs of the three components were then fused based on parameter matrices, which assigned different weights to the results of different components in different regions. Each 
component consists of (1) convolutional layers and (2) residual units. The spatial dependency of any region was captured using a $\mathrm{CNN}$ layer and the residual neural network framework was used to model the temporal closeness, period, and trend properties of tourist flow. Finally, the aggregation was mapped into $[-1,1]$ by a Tanh function, which yielded a faster convergence than the standard logistic function in the process of back-propagation learning.

[Figure 8: Deep spatial-temporal architecture using Residual Network- to go here]

The model used the same data as stage one and two of this study, and assessed tourists use of only six major sites within Freycinet National Park. More sites exist within the Park and were assessed in phase one and two, but for this phase a decision was made to focus only on regions subject to crowding. The results were visualised to calculate the total number of unique tourists' inflow (entry) and outflow (exit) in each of the Freycinet sites. The visualisations of the inflow and outflow counts were then assessed against the actual number of tourists who visited each of the Freycinet sites. Following this, the model was used to determine the number of tourists who visited the same site more than once, as compared to the unique tourists count (Table 1).

Following this, we used the model to determine tourists' mobility over time, in both days (Figure 9) and months (Figure 10). When assessing tourist use of trails over the week days, Saturday appeared as one of the quietest days for all sites. In terms of months, January appeared low but this was due to recruitment beginning later in the month. Subsequent months illustrated that a trend of increasing visitation in February and March to the car park and track head, plus the car park to lookout, visitation from the lookout to the Wineglass Bay declined, possibly due to the weather. 
[Figure 9: Tourist movement by site and weekday, through six Freycinet National Park sites. - to go here]

[Figure 10: Tourist movement by site and month, through six Freycinet National Park sites.

- to go here]

\section{Discussion}

This research sought to bridge a methodological gap between the current state of locationbased technology, the ubiquitous use of smart phones and associated apps and tourism mobility research. Surprisingly, while tourists appear to have changed their behaviour by embracing technology to support their trip planning, in situ decision making and reflection while they travel or following their travels, the use of technology to support tourism research has not displayed a similar rate of change. While Big Data is now being widely discussed and lauded as having strengths in being able to determine macro patterns in travel, its ability to reveal nuanced differences in traveller behaviour is limited, given its reliance on syncing location-based data with that which is sourced from commercial providers such as basic socio-demographic data. Moreover, new privacy rules such as the GDPR will mean that the reliability of large data sets may be comprised. And finally, the reliance of Big Data on factors such as mobile phone reception, data connectivity and/ or Wi-Fi plus Bluetooth, means that its ability to study the movement of tourists (particularly international tourists who may not have data roaming) in national parks may be severely compromised.

As an alternative to Big Data, tourism researchers have used GNSS technology frequently in national parks and remote areas, given its sole reliance on satellite connectivity in order to track the location of tourists. However, this technique has traditionally relied on the syncing of GNSS data that has been generated from a handheld GNSS device, with paper- 
based surveys that determined the travel specific characteristics of study participants. At the time of this research, there were only very few examples of research that had synced GNSS and survey technology and used smart phones to deliver this research (e.g. Thimm and Seepold 2016; Yun and Park 2015) despite what has been described as ubiquitous smart phone use by tourists.

This research demonstrates the potential for tourism mobility researchers and the tourism industry to reconsider its methods. In doing so, it demonstrated how novel digital research such as this can have direct benefits for the infrastructure planning and management in the national parks and protected areas. Five major outcomes have emerged from this study.

\section{Development of a machine-based learning model for tourism mobilities}

This study transitioned mobility analysis from generic Microsoft-based research, to automated tourism-specific research, by translating and accommodating variables of tourist mobilities within the context of GNSS collected location and demographic data sets. This translation resulted in an automated framework, and in doing so, introduced a novel approach to the field of tourism mobilities. Specifically, this study implemented the developed framework considering the concurrent processes of the real world i.e. spatio-temporal processes. By characterising the association of tourist mobility in space and time which is underpinned by human behaviour, we considered the important fundamental principles for space (within the umbrella of proximity, nearby and distant spatial properties) and time (within the umbrella of time window, closeness, period, and trend temporal properties ). These principles and properties are implemented in a computational environment for visualisation. This approach makes contributions to future tourism research in the era of machine-based learning, automation and Big Data. 


\section{Detailed insights into the spatial mobility of tourists in national parks:}

Tourism mobility research has been conceptualised as being made up of three major modes of study: that which relates to the technological aspects of various transport modes; that which relates to the attitudes and behaviours of different tourists or tourism stakeholders; and that which assesses the characteristics that explain or predict travel mode and the factors that influence changes in travel mode (Verbeek and Mommaas 2008). This research contributes to the third mode by using machine-based learning to assess how tourists move through a national park over time. In doing so, our study demonstrates the ability for innovations in tourism mobility research to assess critical issues such as crowding, in real time. This was done by an assessment of the spatial mobility of tourists using real-time integrated GNSS and demographic data. The illustration made with the analysis of FPLand and FPWater mobility shows the spatial territory of choice of the tourists who are visiting Freycinet National Park. This analysis illustrated the spatial heterogeneity of destination of choice. Moreover, the demographic analysis of those who did walk and who did not walk provides insights that can guide future marketing efforts by targeting tourists who are more likely to undertake walks within the national park. In this case, the research revealed that age was found to be a significant variable with younger visitors to the Freycinet Peninsula found to be more active than older visitors. It also revealed that visitors from Australia and Mainland China were less likely to do a walk, while visitors from Hong Kong and other international countries were more likely to do a walk.

The analysis further revealed that those who did longer walks within the park were more likely to have stayed overnight on the Peninsula the night before their walk. This builds upon previous work in urban environments by Shoval et al (2016) and Sugimoto et al (2019) who postulated that the impact of hotel location and transport hubs such as train stations impact on tourist mobility. For natural resource managers, this information provides 
opportunities to conduct marketing to alter visitor flows and in doing so, reduce crowding. Our analysis also highlighted that in the future, a walkability index could be developed to further understand the spatial behaviour of different cohorts. Moreover, further analysis of real-time GNSS data could potentially build advanced spatial behaviour models that address the spatial spill-over effect, diffusion of tourists and spatial homogeneity of tourists within the region.

\section{Detailed insights into the temporal mobility of tourists in Freycinet National Park}

Our study tackled granularity issues associated with real-time GNSS data collection by developing algorithms to aggregate data and answer various social science questions. The experimental design of developing time window of 10 seconds, one minute, two minutes, five minutes, 10 minutes and 20 minutes for data aggregation and quality assurance was suitable to assess mobility over time, or time density. When combined with the demographic data, it revealed that peak hour car park usage was connected to specific demographic segments. For example, those in the car par during peak times were predominantly over 60 , primarily in the state of Tasmania to experience 'wilderness and wildlife' and from Australia, Hong Kong and other countries — but not Chinese visitors. This highly detailed information on infrastructure usage could be extended to develop advanced models of time slicing and time geography for tourist visitation in national parks. Moreover, it builds upon the work of Dickinson et al (2013) on the temporal rhythms of tourists. This research demonstrates the impact that rhythm of arrival have upon crowding and the opportunities for research to alter these rhythms in order to reduce crowding. Given that this app used in this study tracked tourists prior to their arrival at the Wineglass Bay Car Park, there is now an opportunity to conduct experimental research via push notifications, to encourage tourists to visit sites other than the Wineglass Bay Car Park. This would not only reduce crowding, but could potentially 
enhance the visitor experience.

\section{Development of a machine-based learning model for gaining insights into the}

\section{spatio-temporal mobility}

The model developed in this study utilised machine-based learning and was based upon an algorithm that was derived using Relative Complement from Set Theory. By analysing spatial and temporal aspects separately researchers are able to determine basic levels of insight in mobility research. However, in the real world, there are processes where space and time must be considered concurrently and cannot be separated. These processes are termed as spatiotemporal processes. In our model, we consider spatio-temporal dependencies in an integrated way. The spatial dependencies (nearby and distant) and temporal dependencies (closeness, period and trend) facilitates the consideration of the associated complexity.

While this approach has been used in transport, its application to tourism research is unique. It addressed spatio-temporal properties concurrently and was designed so that it could be used to track tourists' movement in close to real time. Ultimately, when used in conjunction with the app that collects data automatically, this model can be incorporated into data dashboards such as $\underline{w w w . t o u r i s m t r a c e r . c o m}$, giving natural resources managers real time visualisations on what is happening out there that will inform decision making.

The model could be further extended to predict tourist mobility patterns by adding more dependencies, such as weather conditions and events that may change the flow of tourists in a certain region. This scenario may also be different in the case of city or town where entry and exit options are varied and tourists may not necessarily entry and exit from the same region. In future research, tourist flows could be modelled and visualised using this approach in developing scenarios of various degrees of sensitivities. 


\section{Evidence-based tourism mobility data for natural resource managers in Freycinet}

\section{National Park}

Alongside the evidence from space time analysis and spatio-temporal modelling, our study provided tangible insights for natural resource managers. As well as highlighting current usage, the data provided insights that could be used to mitigate overcrowding pressures in the over-used car park. For example, it revealed that tourists from China and Hong Kong do not currently visit Friendly Beaches. This, location could be marketed as a 'new' destination for these segments and in doing so, may relieve visitation pressures on the car park. From the data it is also apparent that if an alternate car parking area was to be designed, younger people and those from other overseas countries (excluding those from Hong Kong or China) could be encouraged to park in these alternate areas, as these segments were found to park in the car park for the longest period.

In the longer term, a new walking path (a small segment or a loop) may be developed and marketed to those interested in wilderness and wildlife, over 60 and from other overseas countries. This could mitigate crowding during the busiest time window of the day. A further outcome could be the use of this data to develop a smart parking facility that encouraged shorter stays while generating income. This smart parking facility could be implemented without extending the car park space, but rather, with charges during peak visitation times.

Finally, this study revealed that with consent, an enormous amount of data can be collated and used to understand tourism mobility and inform evidence-based decision making. There are great opportunities to apply tracking to achieve other benefits that extend beyond tourism, such as life logging. The challenge for future researchers is to receive consent for more cost effectives alternatives such as standalone apps; past research has struggled to do so (eg Thimm and Seepold, 2016). The introduction of the European Union's new General Data Protection Regulation (GDPR) that came into effect in May 2018, will 
now prohibit the use of data unless participants opt in to have their data shared. Moreover, changing societal attitudes towards tracking were recently evident during the recent Cambridge Analytica scandal. Thus, the challenge for mobility researchers is to ensure that research practices that track human movement are done with consent and at the same time are able to collect granular information that provides robust and usable data in a timely manner. 


\section{References}

Ahas, R., Aasa, A., Mark, U., Pae, T., and Kull, A. (2007) 'Seasonal tourism spaces in Estonia: Case study with mobile positioning data', Tourism Management 28(3): 898-910.

Ahas, R., Aasa, A., Roose, A., Mark, U., and Silm, S. (2008) 'Evaluating passive mobile positioning data for tourism surveys: An Estonian case study', Tourism Management 29(3): 469-86.

ABS (2011) Tasmania at a Glance. Australian Bureau of Statistics.

http://www.ausstats.abs.gov.au/ausstats/subscriber.nsf/0/06D395C5216E056ACA2578A3001 12ADB/\$File/tas\%20at\%20a\%20glance\%202011.pdf Accessed: 6 October 1016.

Ahas, R, Aasa, A, Mark, Ü, Pae, T, Kull, A (2007) Seasonal tourism spaces in Estonia: Case study with mobile positioning data. Tourism Management, 28: 898-910.

Anuar, F, Gretzel, U (2011) Privacy concerns in the context of location-based services for tourism. In: ENTER 2011 Conference, Innsbruck, Austria.

Asakura, Y and Iryo, T (2007) Analysis of tourist behaviour based on the tracking data collected using mobile communication instrument. Transportation Research Part A: Policy and Practice, 41(7): 684-690. doi:10.1016/j.tra.2006.07.003

Balmford A, Green, JMH, Anderson, M, Beresford, J, Huang, C et al (2015) Walk on the Wild Side: Estimating the Global Magnitude of Visits to Protected Areas. PLoSBiol 13(2) 
Barbosa, H, Barthelemy, M, Ghoshal, G, James, CR, Lenormand, M, Louail, T, Menezes, R, Ramasco, JJ, Simini, F, Tomasini, M (2018) Human mobility: Models and applications, Physics Reports 734: 1-74

Beeco, JA, Hallo, JC (2014) GPS Tracking of Visitor Use: Factors Influencing Visitor Spatial Behavior on a Complex Trail System. Journal of Park and Recreation Administration, 32(2): 43-61.

Beeco, JA, Huang, W-J, Hallo, JC, Norman, WC, McGehee, NG, McGee, J, Goetcheus, C (2013) GPS Tracking of Travel Routes of Wanderers and Planners. Tourism Geographies, 15(3): 551-573.

Birenboim, A, Hegner Reinau, K, Shoval, N, Harder, H (2015) High Resolution Measurement and Analysis of Visitor Experiences in Time and Space: The case of Aalborg Zoo in Denmark. The Professional Geographer, 67(4): 620-629.

Birenboim, A, Anton-Clavé, S, Paolo, Russo, A, Shoval, N (2013) Temporal Activity Patterns of Theme Park Visitors, Tourism Geographies: An International Journal of Tourism, Space, Place and Environment, 15(4): 601-619.

Blečić, I, Canu, D, Cecchini, A, Congiu, T, Fancello, G, Mauro, S, Trunfio, G A (2016, July) Coupling Surveys with GPS Tracking to Explore Tourists' Spatio-Temporal Behaviour. In International Conference on Computational Science and Its Applications. Springer International Publishing, pp 150-160. 
Böhler, S., Grischkat, S., Haustein, S. and Hunecke, M.2006. Encouraging environmentally sustainable holiday travel. Transportation Research, Part A: Policy and Practice, 40(8): 652670.

Buhalis, D, Amaranggnana, A, Smart Tourism Destinations, in Xiang, Z, Tussyadiah, I, Information and Communication Technologies in Tourism 2014, Springer, 553-564.

Connell, J. and page, S. (2008) Exploring the spatial patterms of car- based tourts travel in Lock Lomond and the Trossachs National Park, Scotland. Tourism Management, 29, 561-580. Curry, MR (1997) The digital individual and the private realm. Annals of the Association of American Geographers, 87: 681- 699.

De Cantis, S, Ferrante, M, Kahani, A, and Shoval, N (2016) Cruise Passengers' behavior at the destination: Investigation using GPS technology. Tourism Management, 52: 133-150.

Dickinson, J.E, Filimonau, V, Cherrett, T, Davies, N, Norgate, S, Speed, C, Winstanley, C. (2013) Understanding temporal rhythms and travel behaviour at destinations: potential ways to achieve more sustainable travel. Journal of Sustainable Tourism. 21:7, 1070-1090.

Dou, E, Eklund, P Gretzel, U (2016) Location privacy acceptance: attitudes to transport-based location-aware mobile applications on a university campus. $27^{\text {th }}$ ACIS Conference, Wollongong, Australia, December 5-7, 2016. 
DTF (2016) Labour Force (ABS Cat No 6202.0). Department of Treasury and Finance. http://www.treasury.tas.gov.au/domino/dtf/dtf.nsf/LookupFiles/Labour-

\section{Force.pdf/\$file/Labour-Force.pdf}

Edwards, D, Griffin, T (2013) ‘Understanding Tourists' Spatial Behaviour: GPS Tracking as an Aid to Sustainable Destination Management', Journal of Sustainable Tourism, 21(4): 580595.

Edwards, D, Griffin, T. (2013) Understanding tourists' spatial behaviour: GPS tracking as an aid to sustainable destination management. Journal of Sustainable Tourism: 21 (4) 580-595.

Edwards, D, Dickson, T, Griffin, A, Hayllar, B (2010) Tracking the urban visitor: Methods for examining tourists' spatial behaviour and visual representations. In: Richard, G, Munsters (eds) Cultural tourism research methods, CABI Publishing, Oxford, pp. 104-114.

Garcia-Garcia, A., Orts-Escolano, S., Oprea, S., Villena-Martinez, V., Martinez-Gonzalez, P., \& Garcia-Rodriguez, J. (2018). A survey on deep learning techniques for image and video semantic segmentation. Applied Soft Computing, 70: 41-65.

Girardin, F, J. Blat, F, Calabrese, Dal Fiore, F, Ratti, C (2008) Digital Footprinting: Uncovering Tourists with User-Generated Content, Pervasive Computing, IEEE, 7(4): 36-43.

Gren, M (2001) Time geography matters. In: May, J, Thrift, N (eds) Timespace: Geographies of Temporality. Routledge, London and New York, pp 208-225. 
Gretzel, U (2010) Travel in the Network: Redirected Gazes, Ubiquitous Connections and New Frontiers. In: Levina, M and Kien, G (eds) Post Global Network and Everyday Life, Peter Lang, New York, pp 51-58.

Gretzel, U, Sigala, M, Xiang, Z, Koo, C (2015), Smart tourism: foundations and developments, Electronic Markets 25 (3): 179-188.

Grinberger Y, Shoval, N, McKercher, B (2014) Typologies of Tourists' Time-Space Consumption: A New Approach Using GPS Data and GIS Tools, Tourism Geographies, 16(1): 105-123.

Grinberger, Y, Shoval, N, McKercher, B (2014) Typologies of tourists' time-space consumption: a new approach using GPS data and GIS Tools, Tourism Geographies. 16(1): 105-123. doi=10.1080/14616688.2013.869249

Hagen, K ten, Kramer, R, Modsching, M, Gretzel, U (2006) Capturing the beaten paths: A novel method for analysing tourists' spatial behaviour at an urban destination. ENTER Conference. http://www.vesuv-projekt.de/files/Spatial_Behaviour _Analysis_for_ENTER_MM_RK_KtH_UG_2005-09-09.pdf Accessed 8 July 2019.

Hall, C, M (2005) Reconsidering the Geography of Tourism and Contemporary Mobility, Geographical Research, 43(2):125-139. 
Hallo, J, Beeco, J, Goetcheus, C, McGee, J, Gard McGehee, N, Norman, W (2012) GPS as a Method for Assessing Spatial and Temporal Use Distributions of Nature-Based Tourists. Journal of Travel Research, 51(5): 591-606.

Hardy, A, Aryal, J, and Wells, M (2019) Comparing Techniques for Tracking: The Case of Tourism Tracer in Tasmania, Australia. E-Review of Tourism Research 16(2/3).

Hardy, A and Hyslop, S and Booth, K and Robards, B and Aryal, J and Gretzel, U* and Eccleston, R, (2017) “Tracking tourists' travel with smartphone-based GPS technology: a methodological discussion", Information Technology \& Tourism, 17 (3): 255-274.

Hardy, A and Vorobjovas-Pinta, O and Eccleston, R, (2019) "Enhancing knowledge transfer in tourism: an Elaboration Likelihood Model approach", Journal of Hospitality and Tourism Management, 37: 33-41.

Harwood, A (2011) The Political Constitution of Islandness: The 'Tasmanian problem' and Ten Days on the Island. Unpublished PhD thesis, School of Geography and Environmental Studies, University of Tasmania, Hobart, Australia.

Heerschap, N, Ortega, S, Priem, A, Offermans, M, (2014) Innovation of tourism statistics through the use of new Big Data sources, Statistics Netherlands, The Hague.

Hollenstein, L, Purves, R. (2010) 'Exploring Place through User-Generated Content: Using Flickr Tags to Describe City Cores. Journal of Spatial Information Science, 1: 21-48 
Høyer, K (2000) Sustainable Tourism or Sustainable Mobility? The Norwegian Case. Journal of Sustainable Tourism, 8(2): 147-160.

Hynes, S, Hanley, N, O'Donoghue, C (2013) Alternative treatments of the cost of time in recreational demand models: an application to whitewater kayaking in Ireland. Journal of Environmental Management, 90(2): 1014-1021.

Kellner, L, \& Egger, R (2016) Tracking Tourist Spatial-Temporal Behavior in Urban Places, A Methodological Overview and GPS Case Study. In: Information and Communication Technologies in Tourism 2016, Springer International Publishing, pp 481-494.

Kempermann, A, Chang-Hyeon, J, Timmermans, HJP (2004) Comparing First-Time and Repeat Visitors' Activity Patterns in a Tourism Environment. In: Perdue, RR, Timmermans, HJP, Jysal, M (eds), Consumer Psychology of Tourism, Hospitality and Leisure (vol 3) Lau, G, McKercher, B (2006) Understanding Tourism Movement Patterns in a Destination: A GIS Approach. Tourism and Hospitality Research, 7(1): 39-49.

Lenormand, M, Tugores, A, Colet, P, Ramasco, JJ (2014) Tweets on the Road. PLoS ONE 9(8): e105407. https://doi.org/10.1371/journal.pone.0105407

Lenormand, M, Ramasco, JJ (2016), Towards a better understanding of cities using mobility data, Built Environment 42 (3): 356-364.

Loomis J, Yorizane, S, Larson D (2000) Testing Significance of Multi-Destination and MultiPurpose Trip Effects in a Travel Cost Method Demand Model for Whale Watching Trips. Agricultural and Resource Economics Review, 29(2): 183-191. 
LeCun, Y., Bengio, Y., \& Hinton, G. (2015). Deep learning. Nature, 521: 436.

McKercher, B, Lau, G (2008) Movement Patterns of Tourists Within a Destination. Tourism geographies, 10 (3): 355-374.

McKercher, B, Lau, G (2009) Methodological Considerations when Mapping Tourist Movements Within a Destination. Tourism Analysis 14 (4): 443-455.

McKercher, B, Shoval, N, Ng, E, Birenboim, A (2012) First and Repeat Visitor Behaviour: GPS Tracking and GIS Analysis in Hong Kong. Tourism Geographies, 14(1): 147-161.

McKercher, B, Shoval, N, Park, E, Kahani, A (2015) The Limited Impact of Weather on Tourist Behaviour in an Urban Destination. Journal of Travel Research 54(4): 442 - 455. doi: $10.1177 / 0047287514522880$

Modsching, M, Kramer, R, Hagen, KT, Gretzel, U (2008) Using location-based tracking data to analyze the movements of city tourists. Information Technology \& Tourism, 10(1): 31-42.

Moussouri, T and Roussos, G (2015) Conducting visitor studies using smartphone-based location sensing. Journal of Computing and Cultural Heritage 8(3). doi:10.1145/2677083

O’Connor, A, Zerger, A, Itami, B (2005) Geo-temporal tracking and analysis of tourist movement. Mathematics and Computers in Simulation 69 (1/2): 135-150. 
Parra-López, E, Bulchand-Gidumal, J, Gutiérrez-Taño, D, Díaz-Armas, R (2011) Intentions to use social media in organizing and taking vacation trips. Computers in Human Behavior, 27(2): 640-654. doi:10.1016/j.chb.2010.05.022

Pearce, P, Gretzel, U (2012) Tourism in Technology Dead Zones: Documenting Experiential Dimensions. International Journal of Tourism Sciences, 12(2): 1-20.

Peeters, P. M., Egmond van, T.and Visser, N. 2004. European Tourism, Transport and Environment. Final version. Deliverable 1 for the DG-entr Mustt project., Breda: NHTV Centre for Sustainable Tourism and Transport.

Pettersson, R, Zillinger, M (2011) Time and space in event behavior: Tracking visitors by GPS. Tourism Geographies 13 (1): 1-20.

Prweb.com (2014) A Recent Study Shows that 91\% of iPhone Users are Getting by on a Minimal Level of Storage, and 22\% of All Smartphone Users are Running Out of Space on a Monthly Basis. Accessed online (October 10, 2016) at: http://www.prweb.com/releases/2014/12/prweb12395977.htm

Raun, J, Ahas, R, Tiru, M (2016) Measuring tourism destinations using mobile tracking data. Tourism Management, 57: 202-212.

Robards, B (2013) Friending Participants: Managing the Researcher-Participant Relationship on Social Network Sites. Young, 21(3): 217-235. doi:10.1177/1103308813488815 
Schautz, A M, van Dijk, EM, Meisert, A (2016) The use of audio guides to collect individualized timing and tracking data in a science center exhibition. Visitor Studies 19(1): 96-116.

Shoval, N, Ahas, R (2016) The use of tracking technologies in tourism research: the first decade. Tourism Geographies 18(5): 1-20.

Shoval, N, Isaacson, M (2005) A model of travel itineraries: The application of tracking technologies to the study of pedestrian spatial behaviour. The Professional Geographer 58: $172-183$.

Shoval, N, Isaacson, M (2007) Tracking tourists in the digital age. Annals of Tourism Research, 34: 141-159.

Shoval, N, Isaacson, M., and Chhetri, P. (2014) GPS Smartphones and the Future of Tourism Research, The Wiley Blackwell Companion to Tourism. eds Alan A. Lew, C. Michael Hall, John Wiley and Sons, Ltd, London.

Shoval, N, Kwan, M, Reinau, K, Harder, H (2104) The shoemaker's son always goes barefoot: Implementation of GPS and other tracking technologies for geographic research. Geoforum 51 (1): 1-5.

Shoval, N, McKercher, B, Ng, E, Birenboim, A (2011) Hotel location and tourism activity in cities. Annals of Tourism Research 38 (4): 1594-1612. 
Smith, S (2010) Practical Tourism Research. CABI.

Soutar, P (2015) Personal Communication, Tourism Tasmania, February 2015, Hobart.

Spangenberg, T (2014) Development of a Mobile Toolkit to Support Research on Human Mobility Behaviour Using GPS Trajectories. Information Technology \& Tourism, 14(4): 317346.

Sugimoto, K., Ota, K., Suzuki, S. (2019) Visitor Mobility and Spatial Structure in a Local Urban Tourism Destination: GPS Tracking and Network Analysis, Sustainability, 11(3) : 9; https://doi.org/10.3390/su11030919

Tasmanian Parks and Wildlife Service(2018) Visitors to selected sites (rounded to thousands of visitors). Tasmanian Parks and Wildlife Service: Hobart at: https://www.parks.tas.gov.au/file.aspx?id=49373

Thimm, T, and Seepold, R (2016) Past, present and future of tourist tracking. Journal of Tourism Futures, 2(1): 43-55.

Thornton, P, Williams, A, Shaw, G (1997) Revisiting Time-Space Diaries: An Exploratory Case Study of Tourist Behavior in Cornwall, England. Environment and Planning A, 29(10): $1847-1867$. 
Tourism Australia (2016) Australia welcomes record one million visitors from China. Accessed online (September 1, 2016) at: http://www.tourism.australia.com/news/marketregions-greater-china-17742.aspx Accessed 6 October 2016.

Tourism Research Australia (2016) Tourism Forecasts 2016. Austrade, Australian Government, http://www.tra.gov.au/documents/forecasts/Tourism_Forecasts_2016.pdf Accessed 6 October 2016.

Tussyadiah, I, Wang, D (2015) Tourists' Attitudes towards Proactive Smartphone Systems. Journal of Travel Research 1(1): 1-16.

Tussyadiah, I, Zach, F (2012) The Role of Geo-Based Technology in Place Experiments. Annals of Tourism Research, 39(2): 780-800.

Versichele, M, de Groote, L, Bouuaert, M, Neutens, T, Moerman, I, Van d Weghe, I (2014) Pattern mining in tourist attraction visits through association rule learning on Bluetooth tracking data: A case study of Ghent, Belgium. Tourism Management 22: 67-81.

Wang, D, Park, S, Fesenmaier, D (2012) The Role of Smartphones in Mediating the Touristic Experience. Journal of Travel Research 51(4): 371-387.

Wang, D, Fesenmaier, D R (2013), Transforming the Travel Experience: The Use of Smartphones for Travel, in L Cantoni, Z Xiang (eds) Information and Communication technologies in Tourism, Springer, Berlin and Heidelberg. 
Wang, D, Xiang, Li, X, Li, Y (2013) China's "smart tourism destination" initiative: A taste of the service-dominant logic, Journal of Destination Marketing and Management 2 (2): 59-61.

Wang, D, Park, S. Fesenmaier, D (2014) Adapting to the Mobile World: A Model of Smartphone Use. Annals of Tourism Research 48: 11-26.

Wilken, R (2014) Places nearby: Facebook as a location-based social media platform. New Media \& Society 16, 7: 1087-1103. doi: 10.1177/1461444814543997

Winters, PL, Brabeua, SJ, Georggi, NL (2008) Smart phone application to influence travel behaviours (TRAC-IT Phase 3) (Report no. 549-35).

Wong, TL, Wickham, MD (2015) An examination of Marriott's entry into the Chinese hospitality industry: A Brand Equity perspective. Tourism Management, 48(1): 439-454.

Verbeek, D \& Mommaas, H (2008) Transitions to Sustainable Tourism Mobility: The Social Practices Approach, Journal of Sustainable Tourism, 16(6): 629-644

Xiang, Z, Gretzel, U (2010) Role of social media in online travel information search. Tourism Management, 31(2): 179-188.

Yalowitz, SS, Bronnenkant, K. (2009) Timing and tracking: Unlocking visitor behaviour. Visitor Studies 12(1): 47-64. 
Yoshimura, Y, Sobolevsky, S, Ratti, C (2014) An analysis of visitors' behaviour in the Louvre Museum: a study of using bluetooth data. Environment and Planning B: Planning and Design 41(6): 1113-1131.

Yun, H, and Park, M (2015) Time-Space Movement of Festival Visitors in Rural Areas Using a Smart Phone Application. Asia Pacific Journal of Tourism Research, 20 (11): 1246-1265 Parks and Wildlife Service 2016, Freycinet National Park Management Plan 2000, Department of Primary Industries, Parks, Water and Environment, Hobart.

Zhang, J., Zheng, Y., Qi, D., Li, R., Yi, X., \& Li, T. (2018). Predicting citywide crowd flows using deep spatio-temporal residual networks. Artificial Intelligence, 259: 147-166. 
